\title{
A Writing Intensive Introductory Course for RN to BSN Students
}

By: Anita S. Tesh, Yolanda M. Hyde, Donald D. Kautz

This is a non-final version of an article published in final form in:

Tesh, A.S., Hyde, Y.M., \& Kautz, D.D. (2014). A writing intensive introductory course for RN to BSN students. Nurse Educator, 39(1), 6-7. doi: 10.1097/NNE.0000000000000008

Made available courtesy of Lippincott, Williams \& Wilkins: http://dx.doi.org/10.1097/NNE.0000000000000008

\author{
***@ Lippincott, Williams \& Wilkins. Reprinted with permission. No further reproduction \\ is authorized without written permission from Lippincott, Williams \& Wilkins. This \\ version of the document is not the version of record. Figures and/or pictures may be \\ missing from this format of the document. $* * *$
}

\begin{abstract}
:
This article describes learning strategies used with RN to BSN students in their 1st nursing course to successfully learn how to write formal papers using the American Psychological Association (APA) format. This 1st nursing course, a writing intensive, requires 4 short papers with self, peer, and teacher critiques and opportunities to rewrite. Students learn the style of professional nursing discourse, mastery of APA format, and development of additional skills in following directions and in critiquing their own work. An additional benefit is to enhance learning about professional nursing topics. By mastering writing skills in this initial course, students are able to successfully complete writing assignments in future courses and, in some cases, move on to publication.
\end{abstract}

Keywords: Nursing Education | Writing Intensive Courses

\section{Article:}

\section{Mastery of Writing Abilities}

Written communication skills are essential for evidence-based nursing practice. ${ }^{1}$ Writing skills have been shown to help students gain a greater understanding of content and develop critical thinking abilities. ${ }^{2}$ Troxler et $\mathrm{al}^{3}$ examined how baccalaureate nursing programs teach writing, noting that faculty often find students lacking in ability to write academic papers using the American Psychological Association (APA) format appropriately. In a review of 9 studies, those authors found that sequencing student assignments in a writing-intensive nursing course with feedback from faculty and peers along with an opportunity to revise papers successfully taught students how to write. ${ }^{3}$ However, none of the cited studies included content to help students develop skill in critiquing their own writing. 
At our program, the 1st course for new RN to BSN students is a writing intensive. The goal of the course is to help our RN to BSN students improve their writing skills and their ability to critique their own writing. This course was designed and strategically located in the program to support success in future nursing courses. The teaching strategy we use is to have students write 4 short papers on current nursing topics, using APA format, as the outcome of the course.

Each of papers in the course has clear, specific guidelines. As an adjunct to the assignments, a "paper checklist” is provided to guide students in self- and peer-critique (see Document, Supplemental Digital Content 1,http://links.lww.com/NE/A118). The checklist was derived from the most common mistakes made by earlier RN-BSN students in the course and includes common problems with APA format, organization, and grammar. Finally, "sample” papers are provided for each assignment as guides for students. The sample papers were adapted from actual papers done by prior students, with the students’ permission. They are similar in length and format to the papers requested for assignments; however, to avoid plagiarism, they are focused on topics not currently used for writing assignments in this course. Students learn techniques for self-critique, such as reading one's paper aloud. Students are also encouraged to work with the university writing center on all papers, which most students do.

Sequential Assignments

Students complete 2 assignments before writing papers. The 1st assignment requires students to compare 2 half-page summaries of publications from the same nursing journal article. Categories of analysis include the organization of the paper, development of the sentence structure, grammar critique, and review of clarity and flow. In reality, the summaries were derived, with permission, from actual 1st and 2nd drafts of a paper done by a previous student, versus a publication. After the students discuss which paper is better in the above categories and why, the group discussion is then used as a springboard for faculty to discuss characteristics of professional writing in nursing. For example, we emphasize that professional writing is typically succinct, well organized, and objective. Long, complex sentences and extra descriptive language and content are avoided. Faculty use analogies in the style of other literature to relate to professional nursing publications, that is, nursing literature is more like the style of Ernest Hemingway (simple and direct) than that of Henry James (long, complex, extravagant, and ornate).

Students complete 2 assignments before writing papers. The 1st assignment requires students to compare 2 half-page summaries of publications from the same nursing journal article. Categories of analysis include the organization of the paper, development of the sentence structure, grammar critique, and review of clarity and flow. In reality, the summaries were derived, with permission, from actual 1st and 2nd drafts of a paper done by a previous student, versus a publication. After the students discuss which paper is better in the above categories and why, the group discussion is then used as a springboard for faculty to discuss characteristics of professional writing in nursing. For example, we emphasize that professional writing is typically 
succinct, well organized, and objective. Long, complex sentences and extra descriptive language and content are avoided. Faculty use analogies in the style of other literature to relate to professional nursing publications, that is, nursing literature is more like the style of Ernest Hemingway (simple and direct) than that of Henry James (long, complex, extravagant, and ornate).

As the 2nd assignment, following instruction in APA format, students are given two 1-page article summaries containing a variety of organizational, grammatical, and APA errors. The errors reflect those most commonly seen by faculty teaching the course. Students are directed to find and correct the errors, 1st as an individual assignment, then as a small-group assignment. The 2 papers used in this assignment were also derived, with permission, from former student papers.

Students then progress to the stage of writing their own papers. In paper 1, students write a 1page summary of a nursing journal article, selecting from among 4 articles on the history of nursing provided by faculty. For paper 2, students are asked to describe the "what, who, when, where, and why" of 1 of 3 current professional topics in a 2- to 3-page paper that includes 4 current references. Recent topics include horizontal violence, the nursing shortage, and substance abuse by nurses. Prior to submitting their 2nd paper, students meet with the science librarian who orients them to the library, directs them to resources for the course on the library Web site, and provides her contact information. Many students take advantage of these resources when writing papers 2,3 , and 4 .

The process for papers 1 and 2 is the same. On the day the paper is due, students bring a printed copy of the paper to class. First, they are guided by faculty to critique their own paper, using the paper checklist (see Document, Supplemental Digital Content 1, http://inks.lww.com/NE/A118), guidelines, and a sample paper. Students can make hand corrections of their paper at this time. Next, a peer critiques the paper, using the checklist. Finally, the teacher critiques the paper. Because the papers are short, teachers review the papers during class time while students do another activity. Students leave class with their own notes, the peer's suggestions for revisions, and the teacher's feedback. The teacher retains a photocopy of the paper with the feedback. Students then submit a revised final paper 1 week later. Paper 2 is graded. We found that grading the 1 st submission of paper 2 was a motivation to ensure that students put their best efforts into the 1 st version of the paper.

Paper 3 is the revised version of paper 2, but is graded separately as a new assignment. In addition to making the necessary revisions, students are directed to write a paragraph about what they have learned from the critique process. Students typically write about the value of peer review of their papers, seeing critique of their own paper by a peer, the writing center, learning about APA, becoming aware of current issues in nursing, and how to locate articles and reference. 
When instructors critique papers 1,2 , and 3 , they do not correct the paper for the students. Instead, they indicate the area and type of problem. For example, if a student wrote "The nurse should know their patients’ allergies,” the instructor circles the sentence and writes "noun/pronoun disagreement" rather than correcting the sentence by changing the wording of the sentence. Similarly, an instructor might circle a problematic reference citation in the text and note "see APA manual, page 175." We find that if instructors and peers indicate the specific corrections that should be made, the student makes changes but then commits similar errors in subsequent papers. Indicating the type of error requires the student to determine how to correct the error.

In paper 4, students write on a professional topic, citing research reports. They choose from a list of 6 topics that instructors identified as current topics of nursing research. Students are allowed to write on a topic of their choice if relevant to current practice and deemed appropriate by the faculty. During the process, students are encouraged to seek critique from a colleague and use the writing center before submitting this paper to the instructor. Paper 4 is graded as submitted.

Using self, peer, and instructor critique for all 4 papers rewards students for responding to prior feedback, helps them achieve a high standard in writing, and ensures student success through the process of writing skill development. In addition, students learn the art of constructive selfcritique and become informed about current issues that influence nursing practice. The authors have taught this course each semester for several years and continue to see the students writing abilities improve from paper 1 to paper 4 .

The faculty have reported improvements in the quality of student papers in subsequent courses. These students report retaining the lessons learned about professional writing from this introductory, writing-intensive course and demonstrate the application of these skills. Some students have partnered with faculty to publish articles from the papers they wrote in this course. The most recent example is Susannah Johnson, whose paper 4 became "Beyond the bridge" an evidence-based palliative care model for patients undergoing left-ventricular assist device implementation. ${ }^{4}$

\section{Conclusion}

Professional writing can be intimidating to RNs returning to school. The introductory, writingintensive course described here provides a gradual, yet guided, introduction to professional writing, with various sources of feedback and many opportunities for learning. The format and content of the course encourage use of resources and develop students' skills in self- and peercritique. In particular, students learn to critically review their own written work and get in the habit of doing so before submission of assignments. These practices are invaluable in mastering professional writing.

Acknowledgments 
The authors gratefully acknowledge the editorial assistance and inspiration of Elizabeth Tornquist, MA, FAAN, and the assistance of Dawn Wyrick with this manuscript.

\section{References}

1. Dewar SR. The evidence-based practice course as an opportunity for writing. Nurs Educ. 2012; 37 (4): 143-144.

2. Oermann MH, Hays JC. Writing for Publication in Nursing. 2nd ed. New York: Springer; 2010.

3. Troxler H, Vann JCJ, Oermann MH. How baccalaureate nursing programs teach writing. Nurs Forum. 2011; 46 (4): 280-288.

4. Johnson S, Kautz DD. Beyond the bridge. Nurs Crit Care. 2013; 8 (6): 32-37. 